\title{
PLEBISCITO POPULAR SOBRE LA REFORMA CONSTITUCIONAL EN LA PROVINCIA DE BUENOS AIRES (ARGENTINA)
}

(5 de agosto de 1990)

\author{
JORGE HORACIO OTAÑO PIÑERO \\ Profesor de la Universidad de Morón \\ Secretario de la Cámara Nacional \\ Electoral de la República de Argentina
}



Revista de Derecho Político, núm. 34, 1991, pp. 377-384

\title{
PLEBISCITO POPULAR SOBRE LA REFORMA CONSTITUCIONAL EN LA PROVINCIA DE BUENOS AIRES (ARGENTINA) * \\ (5 de agosto de 1990)
}

\author{
POR \\ JORGE HORACIO OTAÑO PIÑERO ** \\ Profesor de la Universidad de Morón
}

A partir de las elecciones presidenciales del 30 de octubre de 1983, en que la República volvió a la normalidad constitucional, comenzó a gestarse en varias provincias argentinas ideas de reforma de sus Constituciones provinciales, como también en otros niveles, de la reforma de la Constitución Nacional que nos rige desde el año 1853, con algunas modificaciones -años 1860/66/98 y 1957-.

Por ser la Argentina un Estado republicano, representativo y federal -articulo $1 .^{\circ}$ de la Constitución Nacional-, las provincias dictan su propia Constitución bajo el sistema representativo republicano, de acuerdo con los principios, declaraciones y garantias de la Constitución Nacional, debiendo asegurar la administración de justicia, el régimen municipal, y la educación primaria - artículos 106 y $5 .^{\circ}$ de la Constitución Nacional-, cumplidas estas condiciones el gobierno federal garantiza a cada provincia el pleno ejercicio de sus instituciones.

Estas provincias mediante un sistema de elección de convencionales constituyentes, conjuntamente en las elecciones que se llevaron posteriormente a cabo a partir de la fecha indicada, para elegir autoridades nacionales - diputados-, y otras autoridades provinciales y municipales, por imperio de la Ley de simultaneidad de elecciones número 15262 y mediante la adición de otra boleta de votación, lograron constituir sus Convenciones

* Publicado en Boletín Electoral Latinoamericano, núm. 4: Capel San Juan de Costa Rica, 1991. Se reproduce con la autorización del autor.

** Secretario de la Cámara Nacional Electoral de la República de Argentina. 
Constituyentes y luego éstas reformar sus cartas fundamentales. Jujuy, La Rioja, Salta, San Juan, Santiago del Estero, San Luis y Río Negro vivieron de esta manera su reforma constitucional. Córdoba y Catamarca realizaron una votación especial para elegir sus Asambleas Constituyentes, y de esa forma también, reformaron sus cartas fundamentales, llegando así a nueve, de las veintidós provincias, las que optaron por el consenso reformista. Otras se hallan en camino -Formosa, Chaco, Mendoza, Tucumán-.

No ocurrió lo mismo con la Constitución Nacional, debido a que los partidos mayoritarios no se pusieron de acuerdo sobre la profundidad de las modificaciones a realizar. La reflexión de HAURIOU cobra vigencia, cuando decía «Cada reforma de la Constitución implica una nueva fundación del Estado, por eso, la reforma interesa a cada ciudadano y al orden permanente de la República».

Al no obtenerse por parte de ningún partido político las dos terceras partes de votos necesarios en el Congreso para iniciar el proceso de reforma, según lo ordena el artículo 30 de la Constitución Nacional, el tema queda pendiente para un futuro, tal vez, no lejano.

\section{EL PLEBISCITO POPULAR DE LA PROVINCIA DE BUENOS AIRES}

El estado provincial más extenso del país con una superficie de $307.571 \mathrm{~km}^{2}$, tiene el padrón más numeroso con 7.400 .000 electores, divididos en 126 partidos o municipios, y distribuidos en más de 26.577 mesas o centros de votación.

Los aires de reforma también llegaron a la provincia, y luego de largas y profundas discusiones, los partidos mayoritarios - Justicialismo y Radicalismo- se pusieron de acuerdo en tratar la Reforma de la Constitución Provincial, que había sido sancionada el 23 de noviembre de 1934.

Ella establece un procedimiento especial en su artículo 192, que dice:

«a) El proyecto de reforma será tramitado en la forma establecida para la sanción de las leyes, debiendo contar con el voto afirmativo de dos tercios del total de miembros de ambas Cámaras para ser aprobado. La Ley indicará si la reforma será total o parcial $y$, en este último caso, las partes o los artículos que serán reformados;

b) Ia misma Ley establecerá si ha de convocarse o no a una convención reformadora. En este último caso la Ley contendrá la 
enmienda proyectada y ésta será sometida a plebiscito en la primera elección que se realice. El voto será expresado en pro o en contra de la enmienda".

Votada por los dos tercios del total de los miembros de ambas Cámaras Legislativas provinciales, la Ley de reforma deberá indicar si ésta será total o parcial y en este último supuesto los artículos o partes a modificarse.

Los representantes de la voluntad popular entonces encuentran dos cauces para que ésta se exprese; o bien convocar a una Convención Constituyente, o bien someter la Ley aprobada que contiene las enmiendas a un plebiscito en la primera elección que se realice.

A pesar de varios proyectos existentes sobre la necesidad de que la reforma fuese total, los legisladores y una comisión de juristas designadas por el Poder Ejecutivo, consideraron que debía tener carácter parcial y la Ley sometida a plebiscito.

El 5 de diciembre de 1989, el Poder Legislativo sanciona la Ley número 10859, donde establece que los artículos a reformarse son noventa y ocho, debiendo convocarse al electorado de la provincia para que dentro de los ciento ochenta días se exprese en pro o en contra de la enmienda. Pocos días después el Poder Ejecutivo Provincial promulga la Ley votada por ambas Cámaras, mediante Decreto número 5766/89-19/12/89.

Si bien varios constitucionalistas, en estudios seriamente elaborados, propiciaban la imperiosa necesidad sobre la reforma constitucional, la oposición pronto criticó la misma, su procedimiento y la rapidez en que debia realizarse ésta.

Impugnaron de inconstitucionalidad la reforma, ya que la norma indicaba que la "primera elección que se realice" era la venidera y no la convocada "dentro de los ciento ochenta dias de la sanción de la Ley» -artículo 5. ${ }^{\circ}$, Ley número 10859 -. Estos recursos no prosperaron y la elección siguió su proceso, siendo luego la crítica más fuerte, que sólo se buscaba la reelección del titular del Poder Ejecutivo, lo que era prohibido por el artículo 110 vigente.

Ambos partidos mayoritarios -radicales y justicialistas- que habian obtenido casi un 90 por 100 en la última contienda electoral, proclamaron la conveniencia de la reforma y que sus partidarios debian votar el 5 de agosto de 1990 por el Sí.

Los habitantes de los restantes 23 distritos electorales en que se divide el país esperaban con ansiedad el dia del sufragio, ya que esta reforma se convirtió en un hecho polémico, donde varios partidos políticos de oposición descreian sobre la necesidad del cambio, por situaciones de emergencia social existentes, como el poco crecimiento o estancamiento 
del país, que trae como resultados inmediatos la escasez o falta de puestos de trabajo - subempleo o desempleo-, alzas generalizadas de precios -inflación - y demás situaciones colaterales nacidas del problema económico y financiero que se padecen; tornaba inoportuno en estas condiciones someter al electorado a un cambio de los 98 artículos objeto de la reforma, tal vez desusada en nuestra historia constitucional, en donde el pueblo, que gobierna por medio de sus representantes, modifica sus Constituciones por los convencionales constituyentes propuestos por los partidos políticos entre los mejores afiliados o preclaros hombres partidarios, cuya misión es el estudio de los artículos a renovar, y no el pueblo de manera directa en una diversidad de temas que muchas veces escapa al conocimiento del elector más ilustrado.

Las condiciones estaban dadas, entonces, para que la ciudadania libremente determinara con su voto en pro o en contra del cambio constitucional, mediante esa arma tan directa que es el plebiscito, que no sabe de situaciones intermedias; o bendice y santifica con el sí o castiga sin compasión alguna y de manera inapelable con el NO.

Durante las primeras horas de la noche del 5 de agosto se fueron conociendo los resultados provisorios del plebiscito; luego llegaron los definitivos.

Sobre un total de 5.947.492 votos válidos emitidos, el NO contó con 3.909.365, el Sí obtuvo 1.900 .827 , siendo los votos en blanco 117.914 y los votos nulos 19.386 .

CUADRO 1
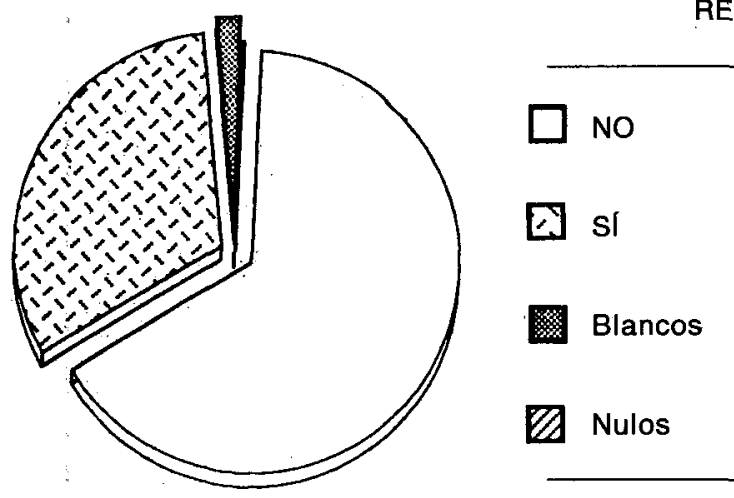

3.909 .365

$65,7 \%$

RESULTADO GENERAL

\begin{tabular}{lcc}
\hline No & 3.909 .365 & $65,7 \%$ \\
\hline sI & 1.900 .827 & $31,9 \%$ \\
Blancos & 117.914 & $1,9 \%$ \\
& & \\
\hline Nulos & 19.386 & $0,3 \%$ \\
\hline
\end{tabular}

Total

5.947 .492 
De los 126 partidos o municipios en que se divide la provincia sólo en tres, y de reducido número de electores, triunfó el Sí; en el resto, el NO se impuso por más de un 60 por 100 de promedio, llegando a más de un 77 por 100 en el partido de Vicente López, que integra con otros el Gran Buenos Aires. En estos municipios que abrazan a la ciudad de Buenos Aires, que contienen gran caudal electoral —Gral. San Martín, 3 de Febrero, La Matanza, Lanús, Avellaneda, etc.-, el NO obtuvo un promedio superior al 65 por 100 .

El resultado del plebiscito, que nadie dudaba a principios del año 1990 que iba a ser por un mayoritario sí, por las fuerzas politicas que lo impulsaban, luego de transcurridos ocho meses, se habia convertido en una derrota con una serie de implicancias totalmente distintas de las que se habian previsto.

¿Qué ocurrió con el resultado plebiscitario? ¿Qué conjeturas se pueden realizar a la luz de las cifras expuestas en el plano adjunto? Sintéticamente, y por la brevedad de estas lineas, las respuestas deben reducirse y van desde la falta de representatividad de la dirigencia política, la cual es desoída a la hora de elegir por la ciudadanía en general, la emancipación del voto cautivo o clientelista de los afiliados a los partidos políticos, que no acatan las órdenes o sugerencias que emanan de las estructuras partidarias, el rechazo a las políticas vigentes, o situaciones puntuales que preocupan al habitante común —falta de seguridad, previsión, salud pública, aumentos excesivos en impuestos, tasas y servicios públicos--, el cual reacciona en forma tajante y busca en el plebiscito el castigo que cree debe dar al gobernante de turno, con su NO. Simplifica el asunto olvidando, tal vez, que con su actitud pierde la posibilidad de modernizar la arquitectura constitucional de la provincia para los años venideros.

Algunos, en cambio, creen ver que en este resultado plebiscitario se da, como en algunos países, un progreso continuo e irreversible de la soberania popular, que sin desconocer tampoco que los mecanismos electorales reflejan el contexto político existente, van madurando, tomando conciencia y dándose cuenta que la gran arma de la democracia es el voto sin ataduras ni condicionamientos, ni tutelaje alguno. Estando, entonces, la ciudadanía mejor preparada para el cambio que la clase dirigente, que no llega a interpretar a sus representados cabalmente.

Otros con sentido tradicional recordarán las palabras de ALBERDI: «El principal medio de afianzar el respeto a la Constitución es evitar en todo lo posible su reforma. Éstas pueden ser necesarias a veces, pero constituyen siempre una crisis pública más o menos grave». 
CuAdro 2

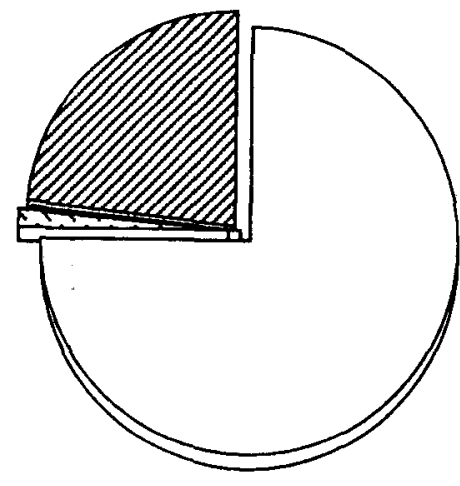

COMPORTAMIENTO ELECTORAL

$\square$ Válidos $\quad 5.810 .192 \quad 74,8 \%$

D Blancos

$117.914 \quad 1,5 \%$

Nulos

19.386

$0,2 \%$

Z Abstención

1.812 .894

$23,3 \%$

Total

7.760 .386 